OPEN ACCESS

Edited by:

Yong Wang,

Guizhou University, China

Reviewed by:

Wei Qinping,

Beijing Academy of Agriculture and Forestry Sciences, China

Roberta Fulthorpe,

University of Toronto Scarborough,

Canada

Joanna Dames,

Rhodes University, South Africa

*Correspondence:

Yuncong Yao

yaoyc_20@126.com

Jie Zhang

anyzj034@126.com

Yan Zhang

360873096@qq.com

${ }^{\dagger}$ These authors have contributed equally to this work

Specialty section:

This article was submitted to Microbe and Virus Interactions with

Plants,

a section of the journal

Frontiers in Microbiology

Received: 13 October 2020 Accepted: 25 January 2021

Published: 12 February 2021

Citation:

Zhang Y, Han M, Song M, Tian J, Song $B$, Hu Y, Zhang $J$ and Yao $Y$ (2021) Intercropping With Aromatic

Plants Increased the Soil Organic

Matter Content and Changed

the Microbial Community in a Pear

Orchard. Front. Microbiol. 12:616932.

doi: 10.3389/fmicb.2021.616932

\section{Intercropping With Aromatic Plants Increased the Soil Organic Matter Content and Changed the Microbial Community in a Pear Orchard}

\author{
Yan Zhang ${ }^{1,2,3 * t,}$ Mingzheng Han ${ }^{1,2,37}$, Mengni Song ${ }^{1,2,3 \dagger}$, Ji Tian ${ }^{1,2,3}$, Beizhou Song 1,2,3, \\ Yujing $\mathrm{Hu}^{1,2,3}$, Jie Zhang ${ }^{1,2,3 *}$ and Yuncong Yao ${ }^{1,2,3 *}$
}

${ }^{1}$ Beijing Advanced Innovation Center for Tree Breeding by Molecular Design, Beijing University of Agriculture, Beijing, China, ${ }^{2}$ College of Plant Science and Technology, Beijing University of Agriculture, Beijing, China, ${ }^{3}$ Beijing Key Laboratory for Agricultural Application and New Technique, Beijing, China

Intercropping influences the soil microbiota via litter and root exudate inputs, but the mechanisms by which root exudates mediate the soil microbial community and soil organic matter (SOM) are still unclear. In this study, we selected three aromatic plants (Ocimum basilicum, Tr1; Satureja hortensis, Tr2; Ageratum houstonianum, Tr3) as intercrops that separately grew between rows of pear trees, and no plants were grown as the control in a pear orchard during the spring-summer season for 3 years. The soil from each plot was collected using a stainless-steel corer by five-point sampling between rows of pear trees. The bacterial and fungal communities of the different aromatic intercrops were analyzed by 165 and ITS rRNA gene amplicon sequencing; their functional profiles were predicted by PICRUSt and FUNGuild analyses. The root exudates of the aromatic plants were analyzed by a liquid chromatographytandem mass spectrometry (LC-MS) system. Compared with the control treatment, all intercropping treatments with aromatic plants significantly increased SOM and soil water content and decreased $\mathrm{pH}$ values. The contents of total nitrogen and alkalihydrolyzable nitrogen in $\operatorname{Tr} 1$ and $\operatorname{Tr} 2$ were higher than those in $\operatorname{Tr} 3 . \operatorname{In} \operatorname{Tr} 3$ soil, the relative content of saccharides increased little, whereas the changes in amine (increases) and alcohols (decreases) were rapid. Ageratum houstonianum intercropping decreased the microbial community diversity and significantly influenced the relative abundances of the dominant microbiota (Actinobacteria, Verrucomicrobia, Gemmatimonadetes, Cyanobacteria, Ascomycota, and Basidiomycota) at the phylum, class, and order levels, which increased the assemblage of functional groups (nitrite ammonification, nitrate ammonification, and ureolysis groups). Our study suggested that the main root exudates from aromatic plants shaped the microbial diversity, structure, and functional groups related to the $\mathrm{N}$ cycle during SOM mineralization and that intercropping with aromatic plants (especially basil and summer savory) increased $\mathrm{N}$ release in the orchard soil.

Keywords: aromatic plants, root exudates, microbial community, soil nutrients, woody-herbaceous intercropping system 


\section{INTRODUCTION}

Soil organic matter (SOM) transformation has the dual benefits of improving soil fertility and maintaining the stability of the soil system (Scholes and Noble, 2001). Understanding the mechanisms of SOM transformation by the microbial community is therefore important, as the capacity of soil carbon (C) and nitrogen (N) cycling may be constrained by aboveground plant species (especially invasive plants) and may thereby influence soil nutrient availability (Chen and Stark, 2000; Sardans et al., 2017).

Soil nutrients are generally delivered by plant litter and root exudates, which are slowly released into the soil through microbial processes and SOM mineralization. These processes can alter the degree of nutrient availability through the mineralization of organic compounds (Arancon et al., 2006; Sharma et al., 2011). The functional gene structure of soil microbial communities could influence the decomposition of SOM and consequently regulate the supply of soil nutrients (Gourmelon et al., 2016; Cheng et al., 2017; Waldrop et al., 2017). Many studies have reported that the structure, composition and diversity of the soil microbial community are influenced by plant species, with plant species differences in litter type and root exudates contributing to variation in the physicochemical properties of soil (Gourmelon et al., 2016; Fitzpatrick et al., 2018; Chen et al., 2020). Consequently, these processes drive different modes of ecological functions and services related to nutrient availability in the soil ecosystem (Lekberg et al., 2013).

Fitzpatrick et al. (2018) found that greater similarity in root microbiomes between hosts leads to negative effects on plant performance through soil feedback, with specific microbial taxa in the endosphere and rhizosphere potentially causing competitive interactions among plant species. Reduced crop productivity in field systems repeatedly planted with the same or closely related plant species is a common phenomenon and has been named replanted disease (Mazzola and Manici, 2012). To avoid replanted disease, intercropping is often used in agroecosystems. Interactions between plants and microbes continue to benefit plants by increasing the acquisition of nutrients, producing growth hormones, and defending against enemies (Berendsen et al., 2012). Economically valuable herbs (e.g., forage and flowering ground cover-plants) are often used as intercrops. The influence of plant species and even different genotypes of the same species on the composition of soil microorganisms is considered to be the largest driving factor for soil C and N cycles (Marschner et al., 2005; Koutika et al., 2007; DeHaan et al., 2010). Many studies have shown that intercropping with ground-cover plants can provide valuable organic C accumulation and has positive effects on soil texture and nutrient availability, with feedback regulating plant growth and crop yield (Atucha et al., 2011; Chen et al., 2014). Intercropping with kura clover in the alleys of a pecan orchard increased the content of soil organic carbon (SOC) and the activity of soil enzymes improved the soil structure and reduced soil erosion (Kremer and Kussman, 2011). Ramos et al. (2010) showed that intercropping in almond (Prunus dulcis L.) orchards improved soil quality by increasing SOC, soil aggregate stability and microbial activity.
The influence of such plant species on soil C accumulation through the regulation of microbial communities has received increasing attention.

Plants used primarily for their aromatic properties in perfumery are defined as aromatic plants in the EU, and they are a source of essential oils, cosmetics and biocides (Lubbe and Verpoorte, 2011; Tang et al., 2013; Song et al., 2014). Intercropping with aromatic plants in an orchard can increase the stability of agroecosystems (Tripathi et al., 2019). Intercropping with certain species of aromatic plants can improve soil quality. For example, intercropping with basil (Ocimum basilicum L.) and summer savory (Satureja hortensis L.) was found to significantly increase soil organic nitrogen and available nitrogen contents in our previous study (Chen et al., 2014). However, only a limited understanding exists of how this intercropping model directly influences the features of the soil microbial community related to the $\mathrm{C}$ and $\mathrm{N}$ cycles via root exudates and plant litter and the subsequent impacts on soil nutrient availability.

In this study, to reveal the mechanisms by which root exudates mediate the soil microbial community and regulate SOM transformation and nutrient cycling in an intercroppings system, three species of aromatic plants were selected as intercrops in a pear orchard. The aims were to determine the following: (i) the influences of root exudates from different aromatic plants on soil nutrient cycling; (ii) the effects of these components on the structure, composition, diversity and function of the soil microbial community; (iii) the correlations among root exudates, the soil microbial community and the soil $\mathrm{C}$ and $\mathrm{N}$ framework in a woody-herbaceous ecosystem; and (iv) the differences among the three intercropping treatments.

\section{MATERIALS AND METHODS}

\section{Experimental Site and Design}

The field experiment was conducted during the spring-summer season 2008-2010 in an organic pear orchard located in the district of Daxing $\left(39^{\circ} 73^{\prime} \mathrm{N}, 116^{\circ} 33^{\prime} \mathrm{E}\right)$, south of Beijing, China. This region is classified as having a temperate, semihumid continental monsoon climate, with a mean annual rainfall of $500 \mathrm{~mm}$ and a mean annual temperature of $11.6^{\circ} \mathrm{C}$. Approximately $76 \%$ of the annual precipitation falls in summer. The orchard, containing 15-year-old Pyrus pyrifolia "Huangin"/P. betulaefolia rootstock trees planted at a spacing of $3 \times 5 \mathrm{~m}$, has been farmed using organic methods since 2005 and has been managed to meet the organic certification standards set by the Organic Food Development Center of China in 2007. During the natural growth of the pear trees, artificial and physical methods were mainly used to control the pear pests in the whole orchard. The soil type is brown soil according to the classification and codes for Chinese soil (GB/T17296-2009). Before the experimental treatments, the topsoil had a $\mathrm{pH}$ of 7.79 , SOM content of $10.30 \mathrm{~g} \mathrm{~kg}^{-1}$, alkali-hydrolyzable nitrogen (AN) content of $151.07 \mathrm{mg} \mathrm{kg}^{-1}$, available phosphorus (AP) content of $49.16 \mathrm{mg} \mathrm{kg}^{-1}$, and available potassium (AK) content of $378.61 \mathrm{mg} \mathrm{kg}^{-1}$. 
The experiment included four treatments: (i) a control, which was a monocropping system of pear tree (no plants were grown between the rows of pear trees, with naturally occurring weeds removed once a month); (ii) Tr1, an intercropping system of pear tree and basil (Ocimum basilicum L); (iii) Tr2, an intercropping system of pear tree and summer savory (Satureja hortensis L.); and (iv) Tr3, an intercropping system of pear trees and blue mink (Ageratum houstonianum Mill.) (Supplementary Figure S1A). There were 12 plots in total, with three plots in each treatment. Each plot was $5 \mathrm{~m}$ wide and $30 \mathrm{~m}$ long and included 20 pear trees (Supplementary Figure S1B). The different treatments were separated from adjacent plots by a $10 \mathrm{~m}$ isolation belt (Supplementary Figure S1A). The intercrops were sown in a greenhouse, and seedlings (approximately $10 \mathrm{~cm}$ in height) were transplanted into the pear orchard in mid-March. The intercrops were grown with a spacing of $0.2 \times 0.3 \mathrm{~m}$ between the rows of pear trees. During the growing period, intertillage weeding was carried out to keep the intercropping area free of weeds. The aromatic plants in the intercropped plots were mowed in late September annually, with the plant residues left in situ.

\section{Soil Sampling and Processing}

Soils from all plots were collected in mid-September 2010 after 3 years of intercropping with aromatic plants (ICAP) or no plants (control). Five soil cores (Supplementary Figure S1C) from each plot were collected using a stainless-steel corer $(4.5 \mathrm{~cm}$ inner diameter, depth $0-20 \mathrm{~cm}$ ) and then mixed to obtain a composite sample for each plot. Thus, each treatment had three replicates of soil samples. The composite samples were immediately sieved $(<2 \mathrm{~mm})$ and divided into three subsamples, which were immediately stored at $-80^{\circ} \mathrm{C}$ for subsequent DNA extraction and soil microbial biomass carbon (MBC) and soil microbial biomass nitrogen $(\mathrm{MBN})$ determination; stored at $4^{\circ} \mathrm{C}$ for analyses of enzymatic activity and the soil water content (SWC); and air dried and stored at room temperature prior to chemical analysis.

\section{Soil Physicochemical Properties and Enzyme Activity Analysis}

Soil moisture content was determined gravimetrically by drying at $105^{\circ} \mathrm{C}$ for $24 \mathrm{~h}$, and the soil $\mathrm{pH}$ was determined in a mixture of soil and water suspension (1:2.5) with a $\mathrm{pH}$ meter (Mettler Toledo FiveEasy Plus, Switzerland) (Lu, 2000). The SOC was determined using the Walkley-Black method, with slight modifications (Nelson and Sommers, 1996). SOM was calculated as SOC $\times 1.724$ (Pribyl, 2010). Total nitrogen (TN) was determined by the Kjeldahl method (Bremner, 1996), and the total phosphorus was determined by the Olsen method (Olsen and Sommers, 1982). AN was detected using the alkaline hydrolysis diffusion method ( $\mathrm{Lu}, 2000)$. Soil invertase, catalase (CAT), and urease activities were determined in accordance with the method described by Jin et al. (2009).

The soil MBC and MBN were measured by the fumigationextraction method (Vance et al., 1987). Briefly, $20 \mathrm{~g}$ of fresh soil (dry weight equivalent) was fumigated with $\mathrm{CH}_{3} \mathrm{Cl}$ for $24 \mathrm{~h}$, and then both fumigated and non-fumigated soils were extracted with $75 \mathrm{~mL}$ of $0.5 \mathrm{M} \mathrm{K}_{2} \mathrm{SO}_{4}$. The extracted solutions were then filtered and analyzed with a Multi N/C 3100 TOC analyzer (Analytik, Jena, Germany). The soil MBC and MBN were calculated as the difference in extractable organic $\mathrm{C}$ and inorganic $\mathrm{N}$ contents, respectively, between fumigated and nonfumigated samples using a conversion factor of 0.45 for both $\mathrm{C}$ and N (Brookes et al., 1985).

\section{Soil DNA Extraction and Sequencing}

Genomic DNA was extracted from a $0.25 \mathrm{~g}$ soil sample using a TIANamp Soil DNA Kit (Tiangen Biotech, Beijing, China) following the manufacturer's procedures. The quality and quantity of DNA were determined by the A260/280 ratio using a NanoDrop device (NanoDrop 2000, Germany) and electrophoresis ( $1 \%$ agarose gel, including a $1 \mathrm{~kb}$ plus ladder). The DNA samples from the soils of the same plot were pooled together and stored at $-80^{\circ} \mathrm{C}$ until PCR amplification. The V3-V4 hypervariable regions of bacterial 16S rRNA was amplified using barcoded primers $341 \mathrm{~F}$ and 785R (Klindworth et al., 2013), and fungal ITS2 regions (ITS3_KYO2F and ITS4_KYO3R) was targeted for amplification through two rounds of PCR (Toju et al., 2012). The purified PCR amplicons were sequenced using the Illumina MiSeq (300 bp paired-end reads) platform from Ori-Gene Technology Co., Ltd. (Beijing, China) in 2016. The high-quality pairedend reads of the $16 \mathrm{~S}$ and ITS sequences were merged using FLASH software (Magoč and Salzberg, 2011) and Mothur $^{1}$ to filter the sequences and remove barcodes. The operational taxonomic units (OTUs) were obtained using the UPARSE pipeline based on the merged sequences (Edgar, 2013), and sequences with $\geq 97 \%$ similarity were assigned to the same OTU. To obtain the taxonomic information of the OTUs, representative sequences of each OTU were generated and aligned against the SILVA and UNITE databases using the RDP classifier ${ }^{2}$ for the 16S and ITS sequences, respectively (Pruesse et al., 2007). The raw sequences were deposited in NCBI's Sequence Read Archive (SRA) under BioProject PRJNA685959.

Alpha-diversity indices, including the number of species observed (Sobs) and the Chao and Shannon indices were calculated with Mothur v.1.34.4 (Schloss et al., 2009). The functional profiles of the bacteria were generated from the Functional Annotation of Prokaryotic Taxa (FAPROTAX) database and associated software ${ }^{3}$ (Louca et al., 2016). Trophic classification of pathotrophs, saprotrophs, and symbiotrophs (for fungi) was performed by FUNGuild ${ }^{4}$ with the use of OTUs as described by Nguyen et al. (2016).

\section{Root Exudate Collection}

The rhizosphere soils of six randomly selected aromatic plants in each plot were pooled into a single rhizosphere soil sample. After shaking off the loosely adhering soil, the tightly adhering

\footnotetext{
${ }^{1}$ https://mothur.org

${ }^{2}$ https://rdp.cme.msu.edu/

${ }^{3}$ www.zoology.ubc.ca/louca/FAPROTAX

${ }^{4}$ http://www.stbates.org/guilds/app.php
} 
TABLE 1 | Basic physicochemical parameters, soil nutrient contents, and enzyme activities in treated and control soil.

\begin{tabular}{|c|c|c|c|c|}
\hline Parameter & Control & Tr1 & Tr2 & Tr3 \\
\hline $\mathrm{pH}$ & $7.81 \pm 0.13 a$ & $7.67 \pm 0.16 b$ & $7.73 \pm 0.04 b$ & $7.67 \pm 0.10 b$ \\
\hline SWC & $8.89 \pm 0.90 b$ & $11.70 \pm 2.37 \mathrm{a}$ & $10.62 \pm 1.56 \mathrm{a}$ & $10.55 \pm 1.47 \mathrm{a}$ \\
\hline SOM & $15.21 \pm 0.77 b$ & $20.33 \pm 1.38 \mathrm{a}$ & $20.46 \pm 1.59 a$ & $20.62 \pm 1.33 \mathrm{a}$ \\
\hline $\mathrm{MBC}$ & $252.44 \pm 20.09 b$ & $361.54 \pm 37.20 \mathrm{a}$ & $330.38 \pm 59.90 \mathrm{a}$ & $318.90 \pm 47.90 a$ \\
\hline MBN & $73.38 \pm 1.17 \mathrm{~d}$ & $88.74 \pm 0.97 b$ & $94.21 \pm 1.27 \mathrm{a}$ & $85.83 \pm 1.44 c$ \\
\hline $\mathrm{MBC} / \mathrm{MBN}$ & $3.26 \pm 0.09 c$ & $4.14 \pm 0.22 \mathrm{a}$ & $3.54 \pm 0.09 b$ & $3.66 \pm 0.11 b$ \\
\hline $\mathrm{TN}$ & $0.83 \pm 0.08 c$ & $1.54 \pm 0.09 a b$ & $1.63 \pm 0.05 a$ & $1.41 \pm 0.05 b$ \\
\hline $\mathrm{TP}$ & $0.59 \pm 0.02 b$ & $0.73 \pm 0.04 a$ & $0.76 \pm 0.03 a$ & $0.65 \pm 0.04 b$ \\
\hline AN & $99.91 \pm 5.79 c$ & $133.57 \pm 13.72 \mathrm{ab}$ & $138.16 \pm 3.26 \mathrm{a}$ & $122.79 \pm 3.51 b$ \\
\hline $\mathrm{C} / \mathrm{N}$ & $10.54 \pm 0.38 \mathrm{a}$ & $7.67 \pm 0.56 \mathrm{bc}$ & $7.30 \pm 0.85 c$ & $8.47 \pm 0.32 b$ \\
\hline N/P & $1.23 \pm 0.05 c$ & $2.24 \pm 0.01 b$ & $2.35 \pm 0.10 b$ & $2.42 \pm 0.05 a$ \\
\hline INV & $5.08 \pm 0.60 b$ & $7.24 \pm 1.16 \mathrm{a}$ & $6.75 \pm 1.42 \mathrm{a}$ & $7.16 \pm 1.09 \mathrm{a}$ \\
\hline CAT & $5.05 \pm 0.44 b$ & $8.01 \pm 0.74 \mathrm{a}$ & $7.74 \pm 1.31 \mathrm{a}$ & $7.75 \pm 1.13 \mathrm{a}$ \\
\hline URE & $13.00 \pm 1.63 b$ & $18.98 \pm 3.19 \mathrm{a}$ & $18.45 \pm 3.33 \mathrm{a}$ & $22.62 \pm 3.04 \mathrm{a}$ \\
\hline
\end{tabular}

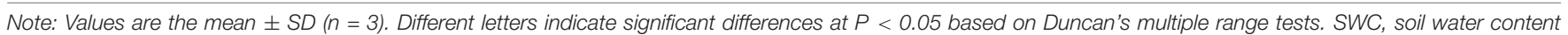

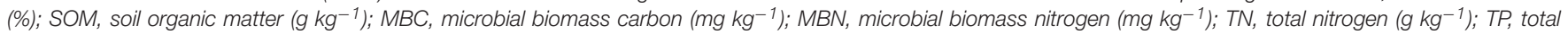

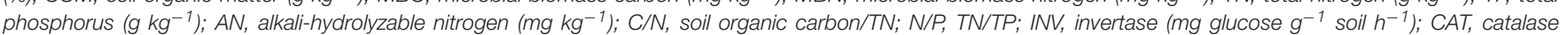

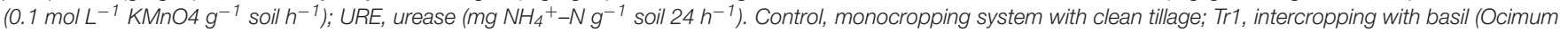
basilicum L.); Tr2, intercropping with summer savory (Satureja hortensis L.); Tr3, intercropping with blue mink (Ageratum houstonianum Mill.).

rhizosphere soil was collected with a brush and passed through a $4 \mathrm{~mm}$ sieve. Then, the rhizosphere soils were placed on ice and immediately transported to the laboratory. In the monocropping system (control), we collected the bare soil between the rows of pear trees in the same way as the rhizosphere soil. Ten grams of each soil sample was stored at $-80^{\circ} \mathrm{C}$ for root exudate collection (Jiang et al., 2017). The stored rhizosphere soil samples (200 mg) were thawed on ice, and metabolites were extracted with $1 \mathrm{~mL}$ of $50 \%$ methanol buffer. Briefly, the mixed solution was vortexed for $1 \mathrm{~min}$, subjected to ultrasound for $20 \mathrm{~min}$ (on ice) and centrifuged $\left(4^{\circ} \mathrm{C}, 10000 \mathrm{rpm}, 15 \mathrm{~min}\right)$, and then $200 \mu \mathrm{L}$ of supernatant extraction mixture was stored overnight at $-20^{\circ} \mathrm{C}$. All samples were analyzed by an AB SCIEX nano LC-MS system (Triple TOF 5600 plus) (SCIEX, United Kingdom) following the manufacturer's instructions. Root exudate determination was carried out by Sugar Pharma Technology Co., Ltd. (Beijing).

\section{Statistical Analysis}

Soil physicochemical properties, soil enzyme activity, soil microbial community alpha-diversity and composition, and root exudate data were submitted to one-way ANOVA followed by Duncan's multiple range test. Differences at $P<0.05$ were regarded as statistically significant. Principal component analysis (PCA) and distance-based redundancy analysis (dbRDA) were used to visualize the associations among soil microbial community parameters, root exudates and environmental variables. Spearman correlation coefficients of pairwise correlations between microbial relative abundance, diversity indicators, soil chemistry, and root exudates were obtained. The statistical analyses and figures were performed using $\mathrm{R}^{5}$.

\footnotetext{
${ }^{5}$ v3.5.1, https://www.r-project.org
}

\section{RESULTS}

\section{Soil Physicochemical Parameters and Enzyme Activities}

The soil physicochemical properties in all treatments are summarized in Table 1. SOM and SWC increased, and $\mathrm{pH}$ was decreased significantly in the intercropping system compared with the monocropping system (control) values in the pear orchard. The SOM content was increased by $33.6 \%$ ( $\operatorname{Tr} 1)$, 34.5\% $(\operatorname{Tr} 2)$, and $35.5 \%(\operatorname{Tr} 3)$ in the intercropping treatments compared with the control. MBC contents increased to a greater extent than MBN content in the intercropping system soil relative to the monocropping system soil values, resulting in an improvement in soil MBC/MBN in the former. The total phosphorus content was increased only in $\operatorname{Tr} 1$ and $\operatorname{Tr} 2$. Moreover, TN and AN contents and N/P were significantly increased, and $\mathrm{C} / \mathrm{N}$ was significantly decreased in the intercropping system soil ( $\operatorname{Tr} 1, \operatorname{Tr} 2$ and $\operatorname{Tr} 3)$ relative to the monocropping system soil. TN and AN contents were higher in $\operatorname{Tr} 1$ and $\operatorname{Tr} 2$ than in $\operatorname{Tr} 3$. In addition, the activities of soil enzymes (invertase, urease, and CAT) were significantly enhanced in the intercropping system soil compared with control soil (Table 1).

\section{Root Exudates of Aromatic Plants in Rhizosphere Soil}

Metabolomics analysis of the relative contents of the root exudates of aromatic plants revealed that the exudates consisted predominantly of saccharides (up to 24.6\%), alcohols (up to $10.5 \%$ ), organic acids (OA, up to $10.0 \%$ ), lipids (up to $7.8 \%$ ), and aromatic compounds (AC, up to 5.7\%) (Figure 1). Root exudation was strongly influenced by the intercropping species. In the intercropping systems, compared with the control, the saccharide, $\mathrm{OA}$ and lipid contents were increased, but the 

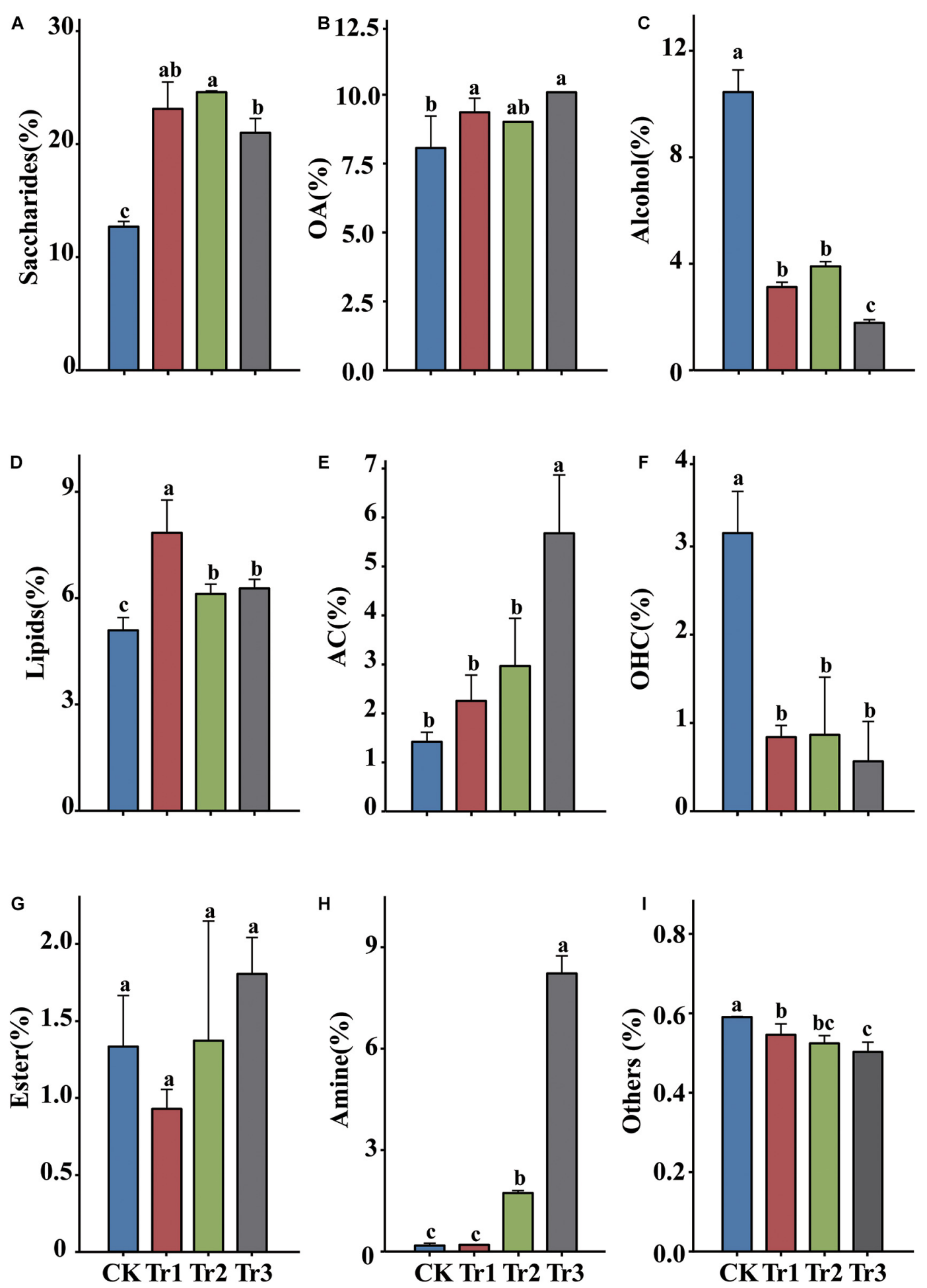

FIGURE 1 | The relative contents of the main root exudate components in rhizosphere soil in intercropping treatments with different species of aromatic plants.

(A) Saccharides, (B) organic acids (OA), (C) alcohol, (D) lipids, (E) aromatic compounds (AC), (F) organic heterocyclic compounds (OHC), (G) esters, (H) amine, and (I) others. Values are the mean $\pm \mathrm{SD}(n=3)$. Different letters indicate significant differences at $P<0.05$ based on Duncan's multiple range test. 
alcohol and organic heterocyclic compound (OHC) contents were reduced significantly. The alcohol and $\mathrm{OHC}$ contents were highest in the control, and the amine and $\mathrm{AC}$ contents were highest in $\operatorname{Tr} 3$ (Figure 1).

The PCA results revealed that the significant differences between the intercropping and monocropping systems were associated with PC1, and that the significant differences among the three aromatic plant intercropping systems were associated with PC2. The PC1 and PC2 components accounted for 59.9\% and $15.4 \%$ of the total variation, respectively (Figure $2 \mathrm{~A}$ ). The $\mathrm{C} / \mathrm{N}$ ratio, $\mathrm{pH}$, alcohol and $\mathrm{OHC}$ contents were significantly positively correlated with each other, while the SWC, SOM, contents of root exudates (AC, saccharides, OA, lipids, amine), contents of $\mathrm{C}$ and $\mathrm{N}$ compounds, and enzyme activities displayed significant positive correlations. The RDA results indicated that soil $\mathrm{pH}$ was positively associated with the contents of root exudates (i.e., alcohols, esters, $\mathrm{OHC}$ ) and was negatively correlated with the contents of soil $\mathrm{C}$ and $\mathrm{N}$ compounds and enzyme activities. In addition, SWC was associated with the contents of $\mathrm{N}$ compounds, saccharides, OA, and AC, and SOM was associated with the contents of $\mathrm{C}$ compounds, saccharides, lipids and amine compounds and CAT activities in the intercropping soil (Figure 2B). The contents of root exudates (saccharides, lipids, OA, AC, amine) were positively related to most soil physicochemical parameters (including soil $\mathrm{C}$ and $\mathrm{N}$ compounds and the activities of associated enzymes) and negatively correlated with soil $\mathrm{pH}$ and the $\mathrm{C} / \mathrm{N}$ ratio; however, alcohol and $\mathrm{OHC}$ contents were positively associated with $\mathrm{pH}$ and the $\mathrm{C} / \mathrm{N}$ ratio (Figure $2 \mathrm{C}$ ).

\section{Composition, Structure, and Diversity of the Soil Bacterial Community}

We sequenced the V3-V4 region of the 16S rRNA gene and obtained a total of 1,968,069 sequences from 12 soil samples $(n=3)$ after filtering. The number of reads ranged from 108,994 to 204,788 , with a mean read count of $164,006 \pm 28,453$. Rarefaction curves implied that the sequencing coverage was sufficient as plateaus were reached for soil communities. Based on the total bacterial community estimated as the number of OTUs, the species richness (Chao index) and alpha-diversity (Shannon index) were enhanced significantly in the intercropping systems with basil and summer savory ( $\operatorname{Tr} 1$ and $\operatorname{Tr} 2)$ but not in the intercropping system with plants of blue mink plants $(\operatorname{Tr} 3)$ compared with the control (Figure 3A).

In all intercropping treatments, nine phyla were dominant: Proteobacteria (26.28\%), Acidobacteria (14.56\%), Actinobacteria (10.14\%), Bacteroidetes (8.96\%), Planctomycetes (7.63\%), Verrucomicrobia (5.70\%), Gemmatimonadetes (5.31\%), Chloroflexi (3.64\%), and Cyanobacteria (1.76\%) (Figure 3B). The intercropping effect of $\operatorname{Tr} 3$ on bacterial community composition was more significant than those of $\operatorname{Tr} 1$ or $\operatorname{Tr} 2$. Intercropping with blue mink ( $\operatorname{Tr} 3$ ) significantly increased the relative abundances (RAs) of Actinobacteria and its dominant classes, orders and families, especially Micrococcales and Micrococcaceae, which both increased in abundance to levels approximately three times those of the control. However, there was no significant
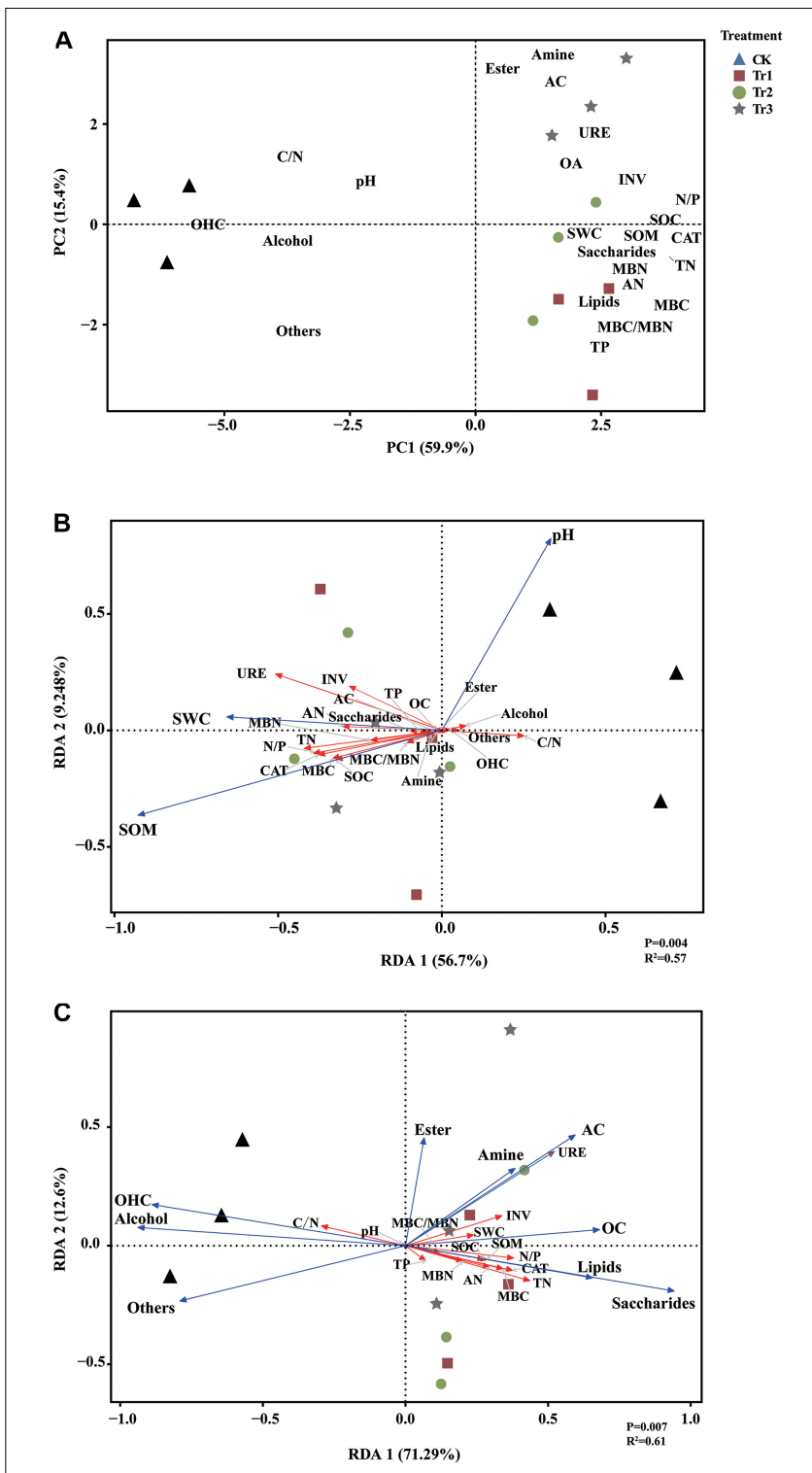

FIGURE 2 | Principal component analysis (PCA) based on the root exudates, soil physicochemical parameters and soil nutrients $(\mathbf{A})$ and redundancy analysis (RDA) of soil nutrient variables constrained by basic physicochemical parameters (pH, SWC, and SOM) (B) and by root exudates (C).

difference in bacterial community composition between the intercropping treatments with basil and summer savory $(\operatorname{Tr} 1$ and $\operatorname{Tr} 2$ ) and the control. Tr3 also significantly increased the RAs of the phylum Verrucomicrobia and its member classes, orders and families and the RAs of the phylum Cyanobacteria and its member classes. Furthermore, Tr3 significantly reduced the RAs of the phylum Gemmatimonadetes and its member classes and genera and those of the class Cytophagia, order Cytophagales, family Cytophagaceae, and genus Ohtaekwangia in the phylum Bacteroidetes. Tr1 significantly increased the RAs of the phylum Verrucomicrobia and its dominant classes, orders and families and those of the phylum Bacteroidetes and its class 
A
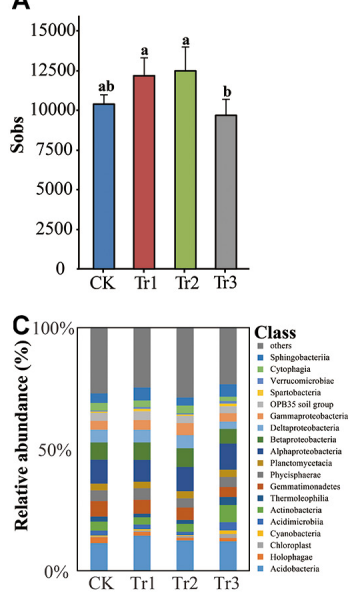

Bacteria
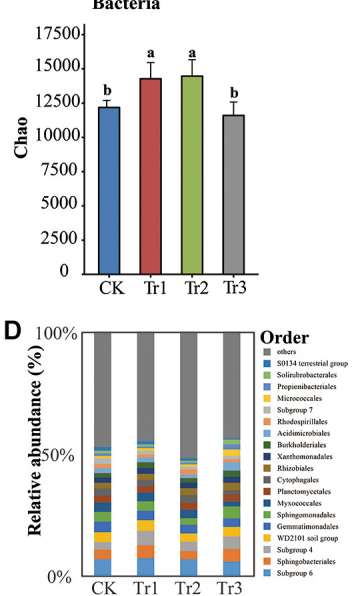
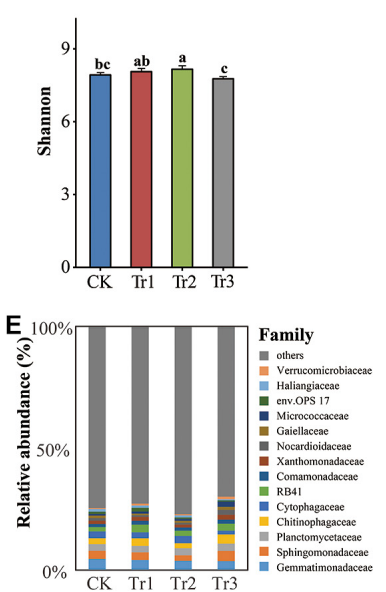

B
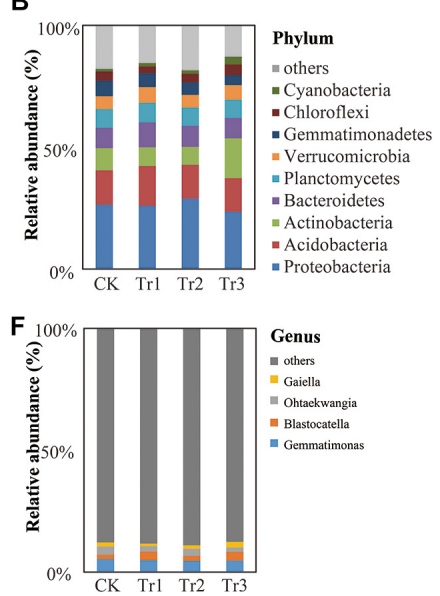

FIGURE 3 | Sobs, Chao, and Shannon indices and phylum-genus composition of the bacterial communities in soil with different species of intercropped aromatic plants, based on the OTUs obtained from 16S rRNA sequencing. (A) Sobs, Chao, and Shannon indices; (B) phylum; (C) class; (D) order; (E) family; and (F) genus. Values are the mean $\pm \mathrm{SD}(n=3)$. Different letters indicate significant differences $(P<0.05)$ based on Duncan's multiple range test. Sobs indicates the number of observed species or operational taxonomic units (OTUs). Chao indicates the non-parametric estimation of asymptotic species richness. Shannon's index was used to assess community diversity.

Sphingobacteriia and order Sphingobacteriales. Tr2 significantly reduced the RAs of the phylum Gemmatimonadetes and its member classes but increased the RA of Gammaproteobacteria. In all of the ICAP treatments, the RA of Holophagae in the phylum Acidobacteria was reduced relative to that in the control by $36.7 \%$ ( $\operatorname{Tr} 1$ ), $54.6 \%$ ( $\operatorname{Tr} 2$ ), and $43.3 \%$ ( $\operatorname{Tr} 3$ ) (Figures 3B-F, Supplementary Figure S2A and Supplementary Table S1).

Based on the FAPROTAX database, we observed that several functions related to the $\mathrm{C}$ cycle were significantly altered by ICAP (Figures 4A,D). Compared with the control, all intercropping treatments significantly reduced the assemblage of fumarate respiration, knallgas bacteria, and ligninolysis groups. In addition, $\operatorname{Tr} 3$ promoted the assemblage of cyanobacteria, methylotrophy, and methanol oxidation groups, and $\operatorname{Tr} 1$ increased the assemblage of cyanobacteria, chitinolysis, and cellulolysis groups (Figures 4A,D). In addition, the assemblage of AC degradation groups showed the largest RA in $\operatorname{Tr} 3$ (Figure 4A). With respect to the assemblage of functional groups related to $\mathrm{N}$ cycling, the nitrite ammonification and nitrate ammonification groups were reduced significantly by ICAP compared with the control, and they were reduced more significantly in $\operatorname{Tr} 3$ than in $\operatorname{Tr} 1$ and $\operatorname{Tr} 2$. The nitrification and aerobic ammonia oxidation groups were reduced, whereas the ureolysis groups were significantly promoted only in $\operatorname{Tr} 3$ (Figures 4B,E). The type of intercropping impacted the structure of the functional groups related to $C$ cycling (Figure 4D) more significantly than that of the functional groups related to $\mathrm{N}$ cycling (Figure 4E).

\section{Composition, Structure, and Diversity of the Soil Fungal Community}

A total of 359,913 quality-filtered fungal ITS2 sequences were obtained from 12 soil samples $(n=3)$. The number of reads ranged from 16,663 to 36,167 with a mean read count of $29,993 \pm 5244$. Rarefaction curves implied that the sequencing coverage was sufficient as plateaus were reached for soil communities. Based on the total fungal community estimated as the OTUs, the Sobs, species richness (Chao index) and alphadiversity (Shannon index) were enhanced significantly by $\operatorname{Tr} 1$ and $\operatorname{Tr} 2$, while the Shannon index was reduced by $\operatorname{Tr} 3$ compared with the control (Figure 5A).

The composition of the total fungal community was dominated by the following phyla: Ascomycota (37.95\%), Basidiomycota (9.75\%), Zygomycota (4.63\%), Glomeromycota (2.20\%), Chytridiomycota (1.15\%), and Ciliophora (0.96\%) (Figure 5B). The RAs of the phylum Ascomycota and its five genera (Ciliophora, Myrothecium, Gibberella, Trichocladium, and Podospora) were all significantly reduced by ICAP relative to the control. The RAs of class Sordariomycetes, order Sordariales, family Chaetomiaceae, and genus Mortierella of Zygomycota were reduced in Tr3 relative to the control, whereas the RA of order Xylariales was promoted significantly by $\operatorname{Tr} 3$. Tr1 also influenced the RAs of these taxa and significantly increased the RAs of Basidiomycota and its member taxa Tremellomycetes, Cystofilobasidiales, Cystofilobasidiaceae, and Guehomyces; the RAs of Chytridiomycota and its member class Chytridiomycetes; and the RA of Glomus of Glomeromycota (Figures 5B-F, Supplementary Figure S2B and Supplementary Table S2).

Based on the FUNGuild database, the analyzed OTUs were assigned to the following guilds: saprotroph, pathotroph, pathotroph-saprotroph-symbiotroph, saprotroph-symbiotroph, symbiotroph, pathotroph-saprotroph, pathogen-saprotrophsymbiotroph, and pathotroph-symbiotroph (Figure 4C). Compared with those in the control, the pathotrophic and saprotrophic groups in ICAP were both reduced significantly. The symbiotic group was promoted by $\operatorname{Tr} 1$ and $\operatorname{Tr} 2$ but reduced by $\operatorname{Tr} 3$ (Figure 4C). The structure of the fungal functional groups 


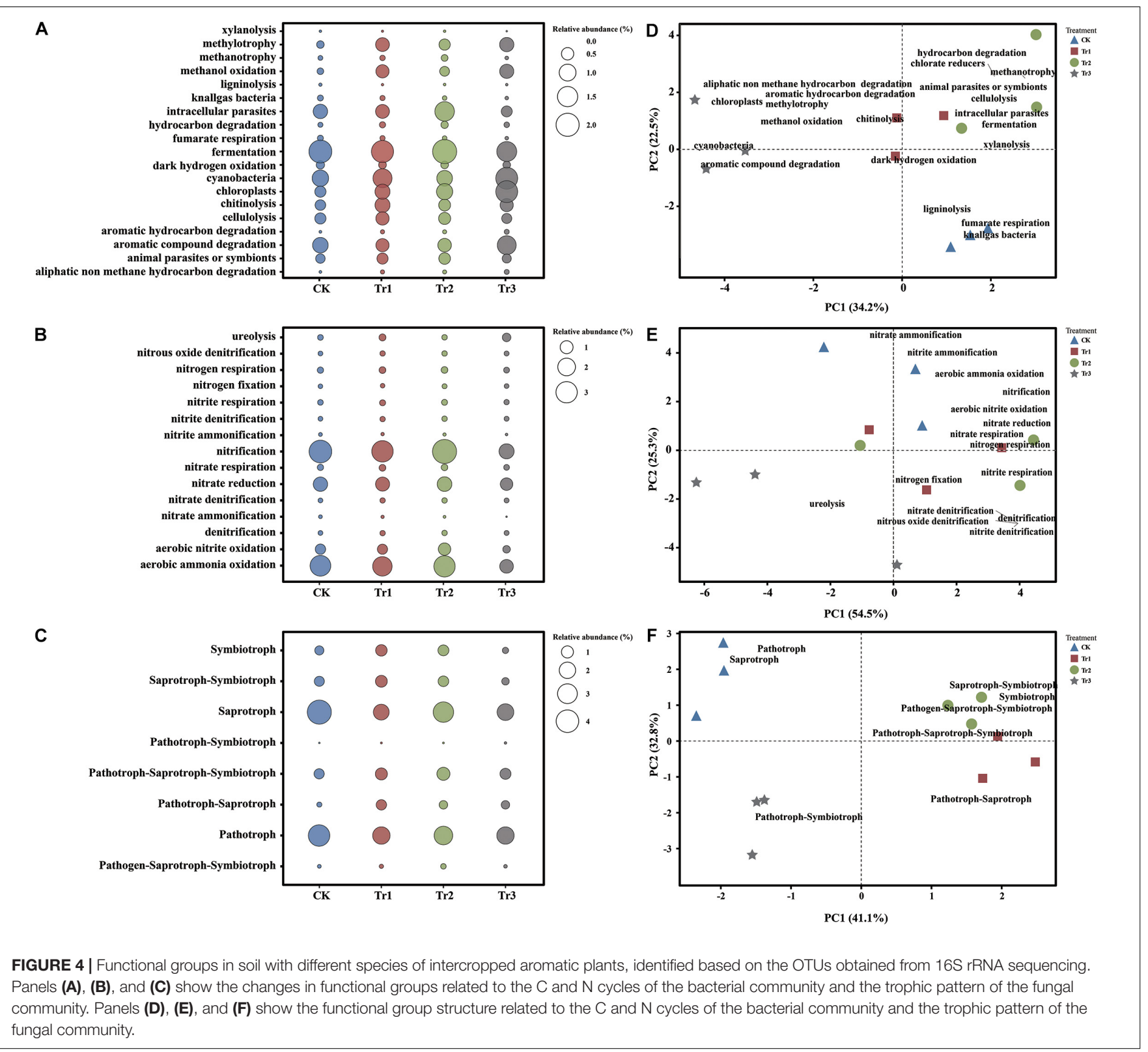

related to trophic patterns indicated a clear separation among the four treatments. The pathotrophic and saprotrophic groups were mainly clustered in the control (Figure 4F).

\section{Relationships Among Soil Properties, Root Exudates, and Microbial Communities}

Analyses of the correlations of root exudates and soil properties revealed that saccharide and $\mathrm{OA}$ contents were positively correlated with SOM, TN content and CAT activity, whereas alcohol and $\mathrm{OHC}$ contents were negatively correlated with these parameters (Figures 6A-E). Regarding microbial diversity, saccharide content was positively correlated with the Sobs and Chao indices of both bacteria and fungi, whereas lipid content was positively correlated with these indices only in fungi. The alcohol content was negatively correlated with the Chao index of fungi, and the amine content was negatively correlated with the Shannon index values of both bacteria and fungi (Figures 6AG). The contents of seven main root exudates (in this study) were associated with the RAs of the dominant soil microbes. For example, saccharide content was mainly positively correlated with the RAs of Basidiomycota and half of its member taxa and negatively correlated with the RAs of Gemmatimonadales and its member families and genera and some taxa of Ascomycota (though it was positively correlated with Leotiomycetes RA) (Figure 6A). OA content was positively correlated with the RAs of Verrucomicrobiae and its orders and families and negatively correlated with those of Cytophagia and its corresponding orders and families, and most taxa in Ascomycota (Figure 6B). With 

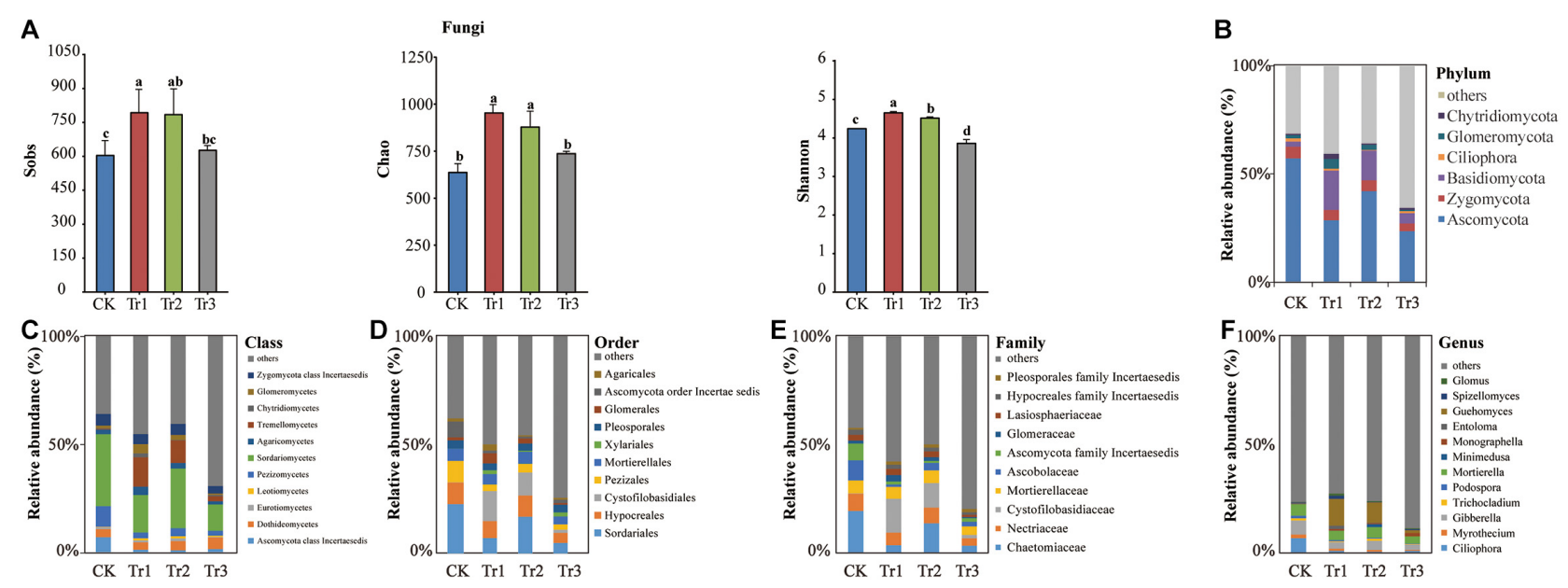

FIGURE 5 | The Sobs, Chao, and Shannon indices and phylum-genus composition of the fungal communities in soil with different species of intercropped aromatic plants, based on the OTUs obtained from ITS rRNA sequencing. (A) Sobs, Chao, and Shannon indices; (B) phylum; (C) class, (D) order; (E) family; and (F) genus. Values are the mean $\pm \mathrm{SD}(n=3)$. Different letters indicate significant differences $(P<0.05)$ based on Duncan's multiple range test. Sobs indicates the number of observed species or operational taxonomic units (OTUs). Chao indicates the non-parametric estimation of asymptotic species richness. Shannon's index was used to assess community diversity.

respect to the functional groups of microbial communities, both saccharide content and OA content correlated negatively with the RAs of ligninolysis, knallgas bacteria, and fumarate respiration groups related to the $\mathrm{C}$ cycle; nitrite ammonification and nitrate ammonification groups related to the $\mathrm{N}$ cycle; and saprotrophic and pathotrophic groups in the fungal trophic structure. Interestingly, the relationships between alcohols and the RAs of the taxonomic groups and functional groups of dominant microbes were largely opposite those between OA content and the RAs of these groups. In addition, the amine content was positively correlated with the RA of a functional group involved in ureolysis and related to the $\mathrm{N}$ cycle (Figure 6D). The AC content was significantly positively correlated with the RAs of Micrococcales and Micrococcaceae (Figure 6G).

Soil organic matter was positively correlated with the contents of $\mathrm{OA}$ and saccharides and negatively correlated with the contents of $\mathrm{OHC}$ and alcohols in root exudates (Figure $6 \mathbf{H}$ ). In addition, SOM was positively related to fungal alpha-diversity (Chao). With respect to the RAs of members of the soil microbial community, SOM was mainly negatively correlated with the RAs of Gemmatimonadetes and its member classes, orders, families and genera and most dominant species of Ascomycota, whereas it was only positively correlated with the RAs of the subgroup 4 of order in Acidobacteria and Leotiomycetes of Ascomycota (Figure 6H). Furthermore, SOM was positively correlated with the RAs of some functional groups, such as those involved in aromatic hydrocarbon degradation and aliphatic non-methane hydrocarbon degradation in the bacterial community, and was negatively correlated with the RAs of others, such as saprotrophic groups of the fungal community and the ligninolysis, fumarate respiration, nitrite ammonification, and nitrate ammonification groups of the bacterial community (Figure 6H).

Soil $\mathrm{pH}$ was positively correlated with the RAs of Rhodospirillales and Zygomycota (including Mortierellales and Mortierellaceae) and negatively correlated with the RAs of Bacteroidetes (including Sphingobacteriia, Sphingobacteriales, and Chitinophagaceae) and Spartobacteria in Verrucomicrobia, as evaluated by genomics analysis (Figure 6I).

\section{DISCUSSION}

\section{Root Exudates Shape the Soil C and N Framework After Intercropping}

Problems with replanting fruit trees (replant disease) have been reported in numerous fruit-growing areas of the world. In tree fruit production, replant problems have been consistently used to describe conditions of poor tree growth resulting from a plethora of potential factors, including diminished soil fertility, degraded soil structure, and residual herbicide activity (Browne et al., 2006). Culture management should emphasize on improving soil microbial and faunal diversity as well as habitat quality rather than focusing on soil disinfection (Winkelmann et al., 2019). Intercropping is often used in orchards of China because it can mitigate disease and increase fruit yield. Intercropping with Tagetes, conventionally used against nematodes, revealed increased growth of apple in two apple replant disease soils, both in a biotest and in field trials (Yim et al., 2017). Plant diversity in experimental systems often enhances ecosystem productivity, but the mechanisms causing this overyielding are only partly understood (Li et al., 2016). In this study, the root system of intercrops (aromatic plants) is mainly distributed at a depth of 0-20 cm, while that of pear trees are mainly distributed at a depth of 20-60 cm. Thus, there is a complementarity between the root distribution depths of the species. Intercropping, the simultaneous cultivation of multiple crop species in a single field, increases aboveground productivity by enhancing soil $\mathrm{C}$ and $\mathrm{N}$ due to species complementarity (Cong et al., 2015). High 


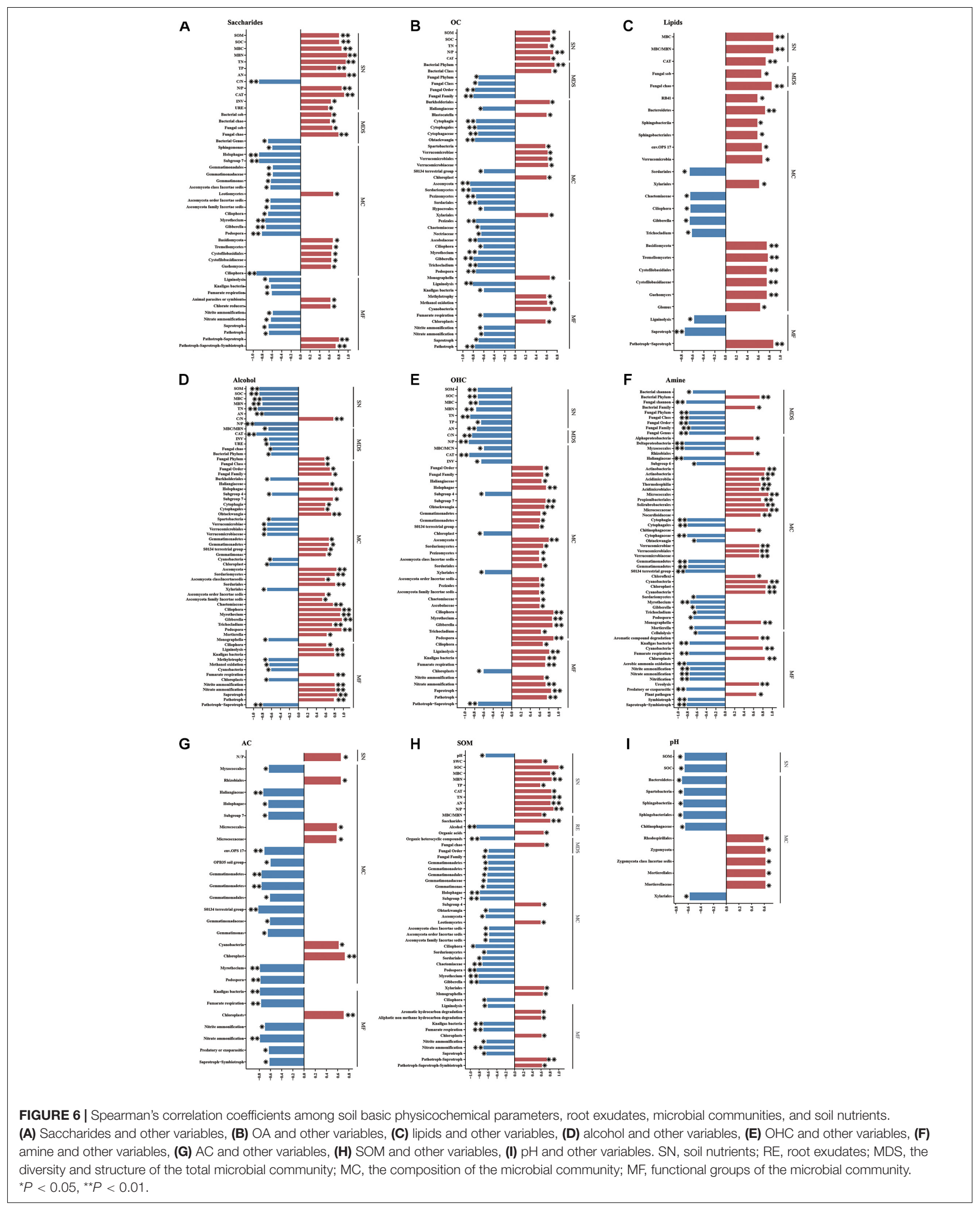


$\mathrm{C}$ and $\mathrm{N}$ stocks in the soil are correlated with soil productivity (Latati et al., 2017).

In this study, ICAP significantly increased the SOM content and promoted the soil enzyme activities (Table 1). These alterations may have been caused by litter and root exudate inputs from the aromatic plants. Previous studies showed that the total amount of soil $\mathrm{C}$ inputs in the undergraded grassland (with high aboveground biomass and living root biomass) was higher than that in degraded grassland due to long-term overgrazing, and root turnover was suggested to be the primary source of soil C inputs (Shen et al., 2020). In our study, the saccharide and OA contents increased while the alcohol and OHC contents decreased after ICAP compared with monocropping. Interestingly, we also found that saccharide and OA contents were positively correlated with SOM, whereas alcohol and OHC contents were negatively correlated with SOM (Figures 6A-E). These results indicated that the changes in root exudates were beneficial for increasing SOM after ICAP. Similarly, a previous study found that SOM can be mobilized by different root exudates (Nardi et al., 2000). Intercropping can contribute to multiple agroecosystem services by increasing yield and improving soil quality and soil $\mathrm{C}$ sequestration (Cong et al., 2015). In addition, the input of litter from aromatic plants may have been responsible for the increase in SOM content under intercropping. Castellano et al. (2015) suggested that plant litter was the primary source of all SOM. However, the processes of litter decomposition and SOM stabilization are often considered separate (Sollins et al., 2007). Carrington et al. (2012) found that plant litter quantity rather than quality is the main determinant of the amount of physicochemically stabilized SOM.

The soil nutrient framework was distinct between the intercropping treatments and the control (Figure 2A). Furthermore, the use of different species in the intercropping system resulted in significant differences in the $\mathrm{N}$ cycle, with higher TN, AN, and MBN contents and a lower $\mathrm{C} / \mathrm{N}$ ratio in the soil associated with basil and summer savory plants ( $\operatorname{Tr} 1$ and $\operatorname{Tr} 2)$ than in that associated with blue mink plants (Tr3) in the intercropping systems. These differences might be caused by variations in the quantity and quality of plant litter and root exudates among intercrops. Highquality plant litters with high $\mathrm{N}$ concentrations and low $\mathrm{C} / \mathrm{N}$ ratios, accelerated greater mineralization efficiency than lowquality litters (Castellano et al., 2015). In addition, plant root exudates can profoundly modify soil microbial communities and influence their $\mathrm{N}$ transformations (Coskun et al., 2017; Meier et al., 2017).

The amount and composition of root exudates varies with the taxonomic status of the host (Chaparro et al., 2014; Mönchgesang et al., 2016; Sasse et al., 2018). In our study, the relative content of AC varied among the different ICAP treatments, with the highest value observed in the $\operatorname{Tr} 3$ treatment. One reason for this finding is that among the intercrops, Ageratum houstonianum (Tr3) had the highest aboveground and root biomass per plant (data not shown). Previous studies showed that higher plant biomass usually induced higher SOM fraction contents (e.g., particulate organic matter, rhizodeposition), which could act as major sources and energy for microorganisms (Tian et al., 2013).

\section{Root Exudates From Different Aromatic Plants Contributed to the Distinct Properties of Microbial Community}

Some studies have shown that the traits of the soil microbial community are influenced by root exudates (Shi et al., 2011; Hu et al., 2018; Sasse et al., 2018). Additionally, root exudate diversity has been identified as a crucial link between plant diversity and soil microorganisms (Steinauer et al., 2016). We found that intercropping with basil and summer savory (Tr1 and $\operatorname{Tr} 2$ ) improved the species richness and alpha-diversity (Chao index) of the bacterial and fungal communities, whereas no significant difference in these measures was observed between the intercropping treatment with blue mink (Tr3) and the control (Figures 3, 5). These differences might be associated with the higher SOM content and lower $\mathrm{pH}$ induced by different aromatic plants. A long-term grassland biodiversity experiment showed that bacterial and fungal diversity increased with higher plant diversity (Lange et al., 2015). Another study showed that intercropping increased microbial OTU richness and fungal community diversity and that the diversity of the soil bacterial community varied among seven intercropping systems ( $\mathrm{Li}$ and $\mathrm{Wu}, 2018)$. These observations show that the intercropping species affects the soil microbial community.

The soil bacterial community displayed two distinct clusters according to the two taxonomic families of the intercrops after ICAP (Supplementary Figure S2A). This finding suggested that the difference in bacterial composition due to interfamily intercropping was larger than that due to intrafamily intercropping. The root exudates of plant species significantly shaped the structure of the rhizosphere bacterial community (Haichar et al., 2008; Sasse et al., 2018). The potential of cropping systems and species identity to modify soil bacterial communities, subsequently modify plant growth and crop-weed competition (Ishaq et al., 2017).

The composition of bacteria was influenced more markedly by blue mink (Tr3) than by basil and summer savory (Tr1 and $\operatorname{Tr} 2)$ (Supplementary Figure S2A). This might have been due to the contents of aromatic AC, OA and amine being highest in the blue mink (Tr3) rhizosphere. A previous study also indicated that OA in root exudates played a significant role in shaping soil bacterial communities (Shi et al., 2011). Furthermore, SOC and AN have been identified as the key factors shaping bacterial communities in the rhizosphere (Cui et al., 2018). In our study, intercropping with blue mink (Tr3) significantly increased the AC content (Figure 1E), the RAs of the phylum Actinobacteria and its order (Micrococcales) and family (Micrococcaceae) (Figures 3B,D,E). Correlation analysis further revealed that the AC content was significantly correlated with Micrococcales and Micrococcaceae (Figure 6G). We suspected that these groups are involved in the degradation of AC. A previous study found strains resistant to heavy metals in nine of the 15 families belonging to the order Micrococcales (Alvarez et al., 2017). With respect to the fungal community, all ICAP treatments significantly reduced the RAs 
of Ascomycota and some of its dominant genera, and the effect of intercropping with blue mink ( $\operatorname{Tr} 3$ ) was more significant than that of intercropping with basil and summer savory $(\operatorname{Tr} 1$ and $\operatorname{Tr} 2)$ (Figure 5B and Supplementary Figure S2B).

The different aromatic plants induced distinct effects on the functional groups of bacteria involved in soil $\mathrm{C}$ and $\mathrm{N}$ cycling (Figure 4). In terms of the functional groups related to $\mathrm{C}$ cycling, all ICAP treatments significantly recruited the cyanobacteria, the RA of cyanobacteria was increased significantly in $\operatorname{Tr} 3$ (Figures 4A,D). Cyanobacteria form the most ancient group of biocrusts and contribute to soil $\mathrm{C}$ and $\mathrm{N}$ cycling (DeBruyn et al., 2011; Chamizo et al., 2012; Zhao et al., 2015; Muñoz-Rojas et al., 2018; Ma et al., 2019). The three intercropping treatments reduced the assemblage of nitrite ammonification and nitrate ammonification groups, and intercropping with blue mink $(\operatorname{Tr} 3)$ significantly promoted the assemblage of the ureolysis group (Figure 4B). In addition, intercropping significantly reduced the saprotrophic and pathotrophic groups of fungal trophic types; such reductions might reduce plant disease. Intercropping has been widely used for its beneficial effects in controlling disease and improving nutrition in the field (Lian et al., 2019; Misra et al., 2019).

\section{Relationships Among SOM, Root Exudates, and Microbial Communities}

Soil bacterial and fungal richness (Sobs and Chao indices) was positively correlated with saccharide content (Figure 6A), whereas the alpha-diversity (Shannon index) was negatively correlated with the content of amine compounds (Figure 6F). These results indicated that saccharide compounds increased the richness of the microbial population while amine compounds inhibited the diversity of the microbial community. A previous study found that $\mathrm{OA}$, amine and alcohol compounds were associated with microbial structure (Zhalnina et al., 2018). These observations suggest that root exudates can stimulate microbes to decompose SOM and release $\mathrm{N}$ with litter input (Strickland et al., 2015; Meier et al., 2017). The relationships between root exudates and the dominant microbial and functional communities identified based on Spearman analysis differed among the treatments (Figure 6). Therefore, different aromatic plants recruit different dominant microbes in intercropping systems; for example, Tr3 significantly increased the RA of Actinobacteria. Yuan et al. (2015) found that banana root exudates, especially $\mathrm{OA}$, played a crucial role in attracting plantgrowth promoting rhizobacteria (PGPR) and initiating their colonization on the host roots.

Soil organic matter was negatively correlated with the RAs of three main bacterial taxa: phylum Gemmatimonadetes and its members Holophagae (belonging to Acidobacteria) and Ohtaekwangia (belonging to Bacteroidetes) (Figure $\mathbf{6 H}$ ). However, $\mathrm{pH}$ was negatively correlated with the RAs of many members of Bacteroidetes and Spartobacteria of Verrucomicrobia and was positively correlated with the RA of Rhodospirillales of Proteobacteria (Figure 6I). Verrucomicrobial elevational distribution was strongly influenced by soil $\mathrm{pH}$ and carbon/nitrogen ratio (Shen et al., 2017). Malik et al. (2018) discovered distinct $\mathrm{pH}$ controls of microbial mechanisms of carbon accumulation. This finding indicated that the combined effect of SOM and $\mathrm{pH}$ shaped the soil decomposition pattern of the dominant bacteria (Hernández et al., 2015; Malik et al., 2018; Martínez-García et al., 2018; Wan et al., 2020).

Additionally, for the fungal community, SOM was positively correlated with fungal alpha-diversity (Chao) and negatively correlated with the RAs of most members of the phylum Ascomycota, whereas $\mathrm{pH}$ was positively correlated with the RAs of some members of Zygomycota. These results are in line with the finding that SOM was more important than $\mathrm{pH}$ in inhibiting the dominant fungi involved in degrading organic materials and in inhibiting pathogen growth (Tian et al., 2016). Furthermore, SOM was positively correlated with the RAs of some functional groups related to the $\mathrm{C}$ cycle and negatively correlated with the RAs of ligninolysis, fumarate respiration, nitrite ammonification, and nitrate ammonification groups of the bacterial community and pathotrophic groups of fungi, whereas $\mathrm{pH}$ was not correlated with the RAs of functional groups (Figure 6). These results suggested that SOM was the main driver of microbial functional groups. Changes in SOM and $\mathrm{pH}$ mediating the microbial community were associated with increases in saccharide and OA contents and decreases in $\mathrm{OHC}$ and alcohol compounds (Tian et al., 2016; Cui et al., 2018; Li et al., 2018).

\section{CONCLUSION}

In conclusion, we found that root exudates from aromatic plants shaped the diversity, structure, composition and function of the soil microbial community, which regulated $\mathrm{C}$ and $\mathrm{N}$ nutrients during SOM decomposition. Intercropping significantly reduced the RAs of saprotrophic and pathotrophic groups. The TN and AN contents, species richness alpha-diversity of bacterial community, and the symbiotic group of the fungal community were higher in $\operatorname{Tr} 1$ and $\operatorname{Tr} 2$ than in $\operatorname{Tr} 3$. We suggest that intercropping with basil and summer savory is more beneficial to pear orchards than intercropping with blue mink. However, the biomass of the intercrops was not determined in this study. To identify the main beneficial factors in intercropping systems, the contents of root exudates and the biomass of intercrops both need to be studied.

\section{DATA AVAILABILITY STATEMENT}

The data presented in the study are deposited in the NCBI repository, accession number (PRJNA685959).

\section{AUTHOR CONTRIBUTIONS}

$\mathrm{MH}, \mathrm{MS}$, JT, BS, and $\mathrm{YH}$ contributed to the data curation. $\mathrm{YY}$ contributed to the funding acquisition. $\mathrm{YZ}, \mathrm{MH}$, and MS contributed to the investigation. $\mathrm{YZ}$ and $\mathrm{JZ}$ contributed to the writing (original draft). YY contributed to the writing (review and 
editing). All authors contributed to the article and approved the submitted version.

\section{FUNDING}

Financial support was provided by the National Key Project of the Research and Development Plan (2016YFD0201116), the Beijing Key Project of the Science and Technology Plan (Z181100002418003/004), Beijing Natural Science Found-Municipal Education Commission (KZ201910020022). The Construction of Beijing Science and Technology Innovation and Service Capacity in Top Subjects (CEFF-PXM2019_014207_000032) and Beijing Key Laboratory of New Techniques in Agricultural Application (NYYYKF201901).

\section{REFERENCES}

Alvarez, A., Saez, J. M., Davila Costa, J. S., Colin, V. L., Fuentes, M. S., Cuozzo, S. A., et al. (2017). Actinobacteria: current research and perspectives for bioremediation of pesticides and heavy metals. Chemosphere 166, 41-62. doi: 10.1016/j.chemosphere.2016.09.070

Arancon, N. Q., Edwards, C. A., and Bierman, P. (2006). Influences of vermicomposts on field strawberries: part 2. effects on soil microbiological and chemical properties. Bioresour. Technol. 97, 831-840. doi: 10.1016/j.biortech. 2005.04.016

Atucha, A., Merwin, I. A., and Brown, M. G. (2011). Long-term effects of four groundcover management systems in an apple orchard. Hortscience 46, 11761183. doi: 10.21273/HORTSCI.46.8.1176

Berendsen, R. L., Pieterse, C. M. J., and Bakker, P. A. H. M. (2012). The rhizosphere microbiome and plant health. Trends Plant Sci. 17, 478-486. doi: 10.1016/j. tplants.2012.04.001

Bremner, J. M. (1996). “Nitrogen-total," in Methods of Soil Analysis, ed. D. L. Sparks (Madison: American Society of Agronomy Inc), 1085-1122.

Brookes, P. C., Landman, A., Pruden, G., and Jenkinson, D. S. (1985). Chloroform fumigation and the release of soil nitrogen: a rapid direct extraction method to measure microbial biomass nitrogen in soil. Soil Biol. Biochem. 17, 837-842. doi: 10.1016/0038-0717(85)90144-0

Browne, G. T., Connell, J. H., and Schneider, S. M. (2006). Almond replant disease and its management with alternative pre-plant soil Fumigation treatments and rootstocks. Plant Dis. 90, 869-876. doi: 10.1094/PD-90-0869

Carrington, E. M., Hernes, P. J., Dyda, R. Y., Plante, A. F., and Six, J. (2012). Biochemical changes across a carbon saturation gradient: lignin, cutin, and suberin decomposition and stabilization in fractionated carbon pools. Soil Biol. Biochem. 47, 179-190. doi: 10.1016/j.soilbio.2011.12.024

Castellano, M. J., Mueller, K. E., Olk, D. C., Sawyer, J. E., and Six, J. (2015). Integrating plant litter quality, soil organic matter stabilization, and the carbon saturation concept. Global Change Biol. 21, 3200-3209. doi: 10.1111/gcb. 12982

Chamizo, S., Cantón, Y., Miralles, I., and Domingo, F. (2012). Biological soil crust development affects physicochemical characteristics of soil surface in semiarid ecosystems. Soil Biol. Biochem. 49, 96-105. doi: 10.1016/j.soilbio.2012.02.017

Chaparro, J. M., Badri, D. V., and Vivanco, J. M. (2014). Rhizosphere microbiome assemblage is affected by plant development. ISME J. 8, 790-803. doi: 10.1038/ ismej. 2013.196

Chen, J., and Stark, J. M. (2000). Plant species effects and carbon and nitrogen cycling in a sagebrush-crested wheatgrass soil. Soil Biol. Biochem. 32, 47-57. doi: 10.1016/S0038-0717(99)00124-8

Chen, X., Song, B., Yao, Y., Wu, H., Hu, J., and Zhao, L. (2014). Aromatic plants play an important role in promoting soil biological activity related to nitrogen cycling in an orchard ecosystem. Sci. Total Environ. 472, 939-946. doi: 10.1016/ j.scitotenv.2013.11.117

\section{ACKNOWLEDGMENTS}

We thank the Beijing Collaborative Innovation Center for Eco-environmental Improvement of Forestry and Fruit Trees; the Key Laboratory of Pomology, Beijing Nursery Engineering Research Center for Fruit Crops; the Key Laboratory of Agricultural Applications at the Beijing University of Agriculture; and the technicians from the Changping District Forestry Administration in Beijing.

\section{SUPPLEMENTARY MATERIAL}

The Supplementary Material for this article can be found online at: https://www.frontiersin.org/articles/10.3389/fmicb. 2021.616932/full\#supplementary-material

Chen, Y., Bonkowski, M., Shen, Y., Griffiths, B. S., Jiang, Y., Wang, X., et al. (2020). Root ethylene mediates rhizosphere microbial community reconstruction when chemically detecting cyanide produced by neighbouring plants. Microbiome 8:4. doi: 10.1186/s40168-019-0775-6

Cheng, L., Zhang, N., Yuan, M., Xiao, J., Qin, Y., Deng, Y., et al. (2017). Warming enhances old organic carbon decomposition through altering functional microbial communities. ISME J. 11:1825. doi: 10.1038/ismej.2017.48

Cong, W., Hoffland, E., Li, L., Six, J., Sun, J., Bao, X., et al. (2015). Intercropping enhances soil carbon and nitrogen. Global Change Biol. 21, 1715-1726. doi: $10.1111 /$ gcb. 12738

Coskun, D., Britto, D. T., Shi, W., and Kronzucker, H. J. (2017). How plant root exudates shape the nitrogen cycle. Trends Plant Sci. 22, 661-673. doi: 10.1016/j. tplants.2017.05.004

Cui, X., Zhang, Y., Gao, J., Peng, F., and Gao, P. (2018). Long-term combined application of manure and chemical fertilizer sustained higher nutrient status and rhizospheric bacterial diversity in reddish paddy soil of Central South China. Sci. Rep. 8:16554. doi: 10.1038/s41598-018-34685-0

DeBruyn, J. M., Nixon, L. T., Fawaz, M. N., Johnson, A. M., and Radosevich, M. (2011). Global biogeography and quantitative seasonal dynamics of Gemmatimonadetes in soil. Appl. Environ. Microbiol. 77, 6295-6300. doi: 10. 1128/AEM.05005-11

DeHaan, L. R., Weisberg, S., Tilman, D., and Fornara, D. (2010). Agricultural and biofuel implications of a species diversity experiment with native perennial grassland plants. Agr. Ecosyst. Environ. 137, 33-38. doi: 10.1016/j.agee.2009.10. 017

Edgar, R. C. J. (2013). UPARSE: highly accurate OTU sequences from microbial amplicon reads. Nat. Methods 10:996. doi: 10.1038/nmeth.2604

Fitzpatrick, C. R., Copeland, J., Wang, P. W., Guttman, D. S., Kotanen, P. M., and Johnson, M. T. (2018). Assembly and ecological function of the root microbiome across angiosperm plant species. Proc. Natl. Acad. Sci. U.S.A. 115, E1157-E1165. doi: 10.1073/pnas.1717617115

Gourmelon, V., Maggia, L., Powell, J. R., Gigante, S., Hortal, S., Gueunier, C., et al. (2016). Environmental and geographical factors structure soil microbial diversity in New Caledonian ultramafic substrates: a metagenomic approach. PloS one 11:e0167405. doi: 10.1371/journal.pone.0167405

Haichar, F. E. Z., Marol, C., Berge, O., Rangel-Castro, J. I., Prosser, J. I., Balesdent, J., et al. (2008). Plant host habitat and root exudates shape soil bacterial community structure. ISME J. 2, 1221-1230. doi: 10.1038/ismej.2008.80

Hernández, M., Dumont, M. G., Yuan, Q., and Conrad, R. (2015). Different bacterial populations associated with the roots and rhizosphere of rice incorporate plant-derived carbon. Appl. Environ. Microbiol. 81, 2244-2253. doi: 10.1128/AEM.03209-14

Hu, L., Robert, C., Cadot, S., Zhang, X., Ye, M., Li, B., et al. (2018). Root exudate metabolites drive plant-soil feedbacks on growth and defense by shaping the rhizosphere microbiota. Nat. Commun. 9:2738. doi: 10.1038/s41467-01805122-7 
Ishaq, S. L., Johnson, S. P., Miller, Z. J., Lehnhoff, E. A., Olivo, S., Yeoman, C. J., et al. (2017). Impact of cropping systems, soil inoculum, and plant species identity on soil bacterial community structure. Microb. Ecol. 73, 417-434. doi: 10.1007/s00248-016-0861-2

Jiang, Y., Liu, M., Zhang, J., Chen, Y., Chen, X., Chen, L., et al. (2017). Nematode grazing promotes bacterial community dynamics in soil at the aggregate level. ISME J. 11, 2705-2717. doi: 10.1038/ismej.2017.120

Jin, K., Sleutel, S., Buchan, D., De Neve, S., Cai, D. X., Gabriels, D., et al. (2009). Changes of soil enzyme activities under different tillage practices in the Chinese Loess Plateau. Soil Till. Res. 104, 115-120. doi: 10.1016/j.still.2009.02.004

Klindworth, A., Pruesse, E., Schweer, T., Peplies, J., Quast, C., Horn, M., et al. (2013). Evaluation of general 16S ribosomal RNA gene PCR primers for classical and next-generation sequencing-based diversity studies. Nucleic Acids Res. 41:e1. doi: 10.1093/nar/gks808

Koutika, L. S., Vanderhoeven, S., Chapuis-Lardy, L., Dassonville, N., and Meerts, P. (2007). Assessment of changes in soil organic matter after invasion by exotic plant species. Biol. Fert. Soils 44, 331-341. doi: 10.1007/s00374-007-0210-1

Kremer, R. J., and Kussman, R. D. (2011). Soil quality in a pecan-kura clover alley cropping system in the Midwestern USA. Agroforest. Syst. 83, 213-223. doi: 10.1007/s10457-011-9370-y

Lange, M., Eisenhauer, N., Sierra, C. A., Bessler, H., Engels, C., Griffiths, R. I., et al. (2015). Plant diversity increases soil microbial activity and soil carbon storage. Nat. Commun. 6:6707. doi: 10.1038/ncomms7707

Latati, M., Aouiche, A., Tellah, S., Laribi, A., Benlahrech, S., Kaci, G., et al. (2017). Intercropping maize and common bean enhances microbial carbon and nitrogen availability in low phosphorus soil under Mediterranean conditions. Eur. J. Soil Biol. 80, 9-18. doi: 10.1016/j.ejsobi.2017.03.003

Lekberg, Y., Gibbons, S. M., Rosendahl, S., and Ramsey, P. W. (2013). Severe plant invasions can increase mycorrhizal fungal abundance and diversity. ISME J. 7:1424. doi: 10.1038/ismej.2013.41

Li, B., Li, Y., Wu, H., Zhang, F., Li, C., Li, X., et al. (2016). Root exudates drive interspecific facilitation by enhancing nodulation and $\mathrm{N}_{2}$ fixation. Proc. Natl Acad. Sci. 113, 6496-6501. doi: 10.1073/pnas.1523580113

Li, Q., Liu, C., Wang, X., Jin, Z., Song, A., Liang, Y., et al. (2018). Influence of altered microbes on soil organic carbon availability in karst agricultural soils contaminated by $\mathrm{Pb}-\mathrm{Zn}$ tailings. Front. Microbiol. 9:2062. doi: 10.3389/fmicb. 2018.02062

Li, S., and Wu, F. (2018). Diversity and co-occurrence patterns of soil bacterial and fungal communities in seven intercropping systems. Front. Microbiol. 9:1521. doi: $10.3389 /$ fmicb. 2018.01521

Lian, T., Mu, Y., Jin, J., Ma, Q., Cheng, Y., Cai, Z., et al. (2019). Impact of intercropping on the coupling between soil microbial community structure, activity, and nutrient-use efficiencies. PeerJ 7:e6412. doi: 10.7717/peerj.6412

Louca, S., Parfrey, L. W., and Doebeli, M. (2016). Decoupling function and taxonomy in the global ocean microbiome. Science 353, 1272-1277. doi: 10 . $1126 /$ science.aaf 4507

Lu, R. K. (2000). Methods of Soil and Agro-Chemical Analysis (in Chinese). Beijing: China Agricultural Science and Technology Press.

Lubbe, A., and Verpoorte, R. (2011). Cultivation of medicinal and aromatic plants for specialty industrial materials. Ind. Crop. Prod. 34, 785-801. doi: 10.1016/j. indcrop.2011.01.019

Ma, X., Zhang, Q., Zheng, M., Gao, Y., Yuan, T., Hale, L., et al. (2019). Microbial functional traits are sensitive indicators of mild disturbance by lamb grazing. ISME J. 13, 1370-1373. doi: 10.1038/s41396-019-0354-7

Magoč, T., and Salzberg, S. L. (2011). FLASH: fast length adjustment of short reads to improve genome assemblies. Bioinformatics 27, 2957-2963. doi: 10.1093/ bioinformatics/btr507

Malik, A. A., Puissant, J., Buckeridge, K. M., Goodall, T., Jehmlich, N., Chowdhury, S., et al. (2018). Land use driven change in soil pH affects microbial carbon cycling processes. Nat. Commun. 9:3591. doi: 10.1038/s41467-018-05980-1

Marschner, P., Grierson, P. F., and Rengel, Z. (2005). Microbial community composition and functioning in the rhizosphere of three Banksia species in native woodland in Western Australia. Appl. Soil Ecol. 28, 191-201. doi: 10. 1016/j.apsoil.2004.09.001

Martínez-García, L. B., Korthals, G., Brussaard, L., Jørgensen, H. B., and De Deyn, G. B. (2018). Organic management and cover crop species steer soil microbial community structure and functionality along with soil organic matter properties. Agr. Ecosyst. Environ. 263, 7-17. doi: 10.1016/j.agee.2018. 04.018

Mazzola, M., and Manici, L. M. (2012). Apple replant disease: role of microbial ecology in cause and control. Annu. Rev. Phytopathol. 50, 45-65. doi: 10.1146/ annurev-phyto-081211-173005

Meier, I. C., Finzi, A. C., and Phillips, R. P. (2017). Root exudates increase N availability by stimulating microbial turnover of fast-cycling $\mathrm{N}$ pools. Soil Biol. Biochem. 106, 119-128. doi: 10.1016/j.soilbio.2016.12.004

Misra, P., Maji, D., Awasthi, A., Pandey, S. S., Yadav, A., Pandey, A., et al. (2019). Vulnerability of soil microbiome to monocropping of medicinal and aromatic plants and its restoration through intercropping and organic amendments. Front. Microbiol. 10:2604. doi: 10.3389/fmicb.2019.02604

Mönchgesang, S., Strehmel, N., Schmidt, S., Westphal, L., Taruttis, F., Müller, E., et al. (2016). Natural variation of root exudates in Arabidopsis thaliana-linking metabolomic and genomic data. Sci. Rep. 6:29033. doi: 10.1038/srep29033

Muñoz-Rojas, M., Román, J. R., Roncero-Ramos, B., Erickson, T. E., Merritt, D. J., Aguila-Carricondo, P., et al. (2018). Cyanobacteria inoculation enhances carbon sequestration in soil substrates used in dryland restoration. Sci. Total Environ. 636, 1149-1154. doi: 10.1016/j.scitotenv.2018.04.265

Nardi, S., Concheri, G., Pizzeghello, D., Sturaro, A., Rella, R., and Parvoli, G. (2000). Soil organic matter mobilization by root exudates. Chemosphere 41, 653-658. doi: 10.1016/s0045-6535(99)00488-9

Nelson, D. W., and Sommers, L. E. (1996). "Total carbon, organic carbon, and organic matter," in Methods of Soil Analysis, ed. D. L. Sparks (Madison: American Society of Agronomy Inc), 961-1010.

Nguyen, N. H., Song, Z., Bates, S. T., Branco, S., Tedersoo, L., Menke, J., et al. (2016). FUNGuild: an open annotation tool for parsing fungal community datasets by ecological guild. Fungal Ecol. 20, 241-248. doi: 10.1016/j.funeco. 2015.06.006

Olsen, S. R., and Sommers, L. E. (1982). "Phosphorous," in Methods of Soil Analysis, eds A. L. Page, R. H. Miller, and D. R. Keeney (Madison: American Society of Agronomy Inc), 403-427.

Pribyl, D. W. (2010). A critical review of the conventional SOC to SOM conversion factor. Geoderma 156, 75-83. doi: 10.1016/j.geoderma.2010.02.003

Pruesse, E., Quast, C., Knittel, K., Fuchs, B. M., Ludwig, W., Peplies, J., et al. (2007). SILVA: a comprehensive online resource for quality checked and aligned ribosomal RNA sequence data compatible with ARB. Nucleic Acids Res. 35, 7188-7196. doi: 10.1093/nar/gkm864

Ramos, M. E., Benítez, E., García, P. A., and Robles, A. B. (2010). Cover crops under different managements vs. frequent tillage in almond orchards in semiarid conditions: effects on soil quality. Appl. Soil Ecol. 44, 6-14. doi: 10.1016/j.apsoil. 2009.08.005

Sardans, J., Bartrons, M., Margalef, O., Gargallo-Garriga, A., Janssens, I. A., Ciais, P., et al. (2017). Plant invasion is associated with higher plant-soil nutrient concentrations in nutrient-poor environments. Global Change Biol. 23, 12821291. doi: $10.1111 / \mathrm{gcb} .13384$

Sasse, J., Martinoia, E., and Northen, T. (2018). Feed your friends: do plant exudates shape the root microbiome? Trends Plant Sci. 23, 25-41. doi: 10.1016/j.tplants. 2017.09.003

Schloss, P. D., Westcott, S. L., Ryabin, T., Hall, J. R., Hartmann, M., Hollister, E. B., et al. (2009). Introducing mothur: open-source, platform-independent, community-supported software for describing and comparing microbial communities. Appl. Environ. Microbiol. 75, 7537-7541. doi: 10.1128/AEM. 01541-09

Scholes, R. J., and Noble, I. R. (2001). Storing carbon on land. Science 294, 1012-1013.

Sharma, A., Tiwari, K. N., and Bhadoria, P. B. S. (2011). Effect of land use land cover change on soil erosion potential in an agricultural watershed. Environ. Monit. Assess. 173, 789-801. doi: 10.1007/s10661-010-1423-6

Shen, C., Ge, Y., Yang, T., and Chu, H. (2017). Verrucomicrobial elevational distribution was strongly influenced by soil $\mathrm{pH}$ and carbon/nitrogen ratio. J. Soil Sediment 17, 2449-2456. doi: 10.1007/s11368-017-1680-x

Shen, X., Yang, F., Xiao, C., and Zhou, Y. (2020). Increased contribution of root exudates to soil carbon input during grassland degradation. Soil Biol. Biochem. 146:107817. doi: 10.1016/j.soilbio.2020.107817

Shi, S., Richardson, A. E., O'Callaghan, M., DeAngelis, K. M., Jones, E. E., Stewart, A., et al. (2011). Effects of selected root exudate components on soil bacterial 
communities. FEMS Microbiol. Ecol. 77, 600-610. doi: 10.1111/j.1574-6941. 2011.01150.x

Sollins, P., Swanston, C., and Kramer, M. (2007). Stabilization and destabilization of soil organic matter-a new focus. Biogeochemistry 85, 1-7. doi: 10.1007/ s10533-007-9099-X

Song, B., Jiao, H., Tang, G., and Yao, Y. (2014). Combining repellent and attractive aromatic plants to enhance biological control of three tortricid species (Lepidoptera: Tortricidae) in an apple orchard. Fla. Entomol. 97, 1679-1689. doi: 10.1653/024.097.0442

Steinauer, K., Chatzinotas, A., and Eisenhauer, N. (2016). Root exudate cocktails: the link between plant diversity and soil microorganisms? Ecol. Evol. 6, 73877396. doi: 10.1002/ece3.2454

Strickland, M. S., McCulley, R. L., Nelson, J. A., and Bradford, M. A. (2015). Compositional differences in simulated root exudates elicit a limited functional and compositional response in soil microbial communities. Front. Microbiol. 6:817. doi: $10.3389 /$ fmicb.2015.00817

Tang, G. B., Song, B. Z., Zhao, L. L., Sang, X. S., Wan, H. H., Zhang, J., et al. (2013). Repellent and attractive effects of herbs on insects in pear orchards intercropped with aromatic plants. Agroforest. Syst. 87, 273-285. doi: 10.1007/s10457-0129544-2

Tian, J., Dippold, M., Pausch, J., Blagodatskaya, E., Fan, M., Li, X., et al. (2013). Microbial response to rhizodeposition depending on water regimes in paddy soils. Soil Biol. Biochem. 65, 195-203. doi: 10.1016/j.soilbio.2013.05.021

Tian, J., Wang, J., Dippold, M., Gao, Y., Blagodatskaya, E., and Kuzyakov, Y. (2016). Biochar affects soil organic matter cycling and microbial functions but does not alter microbial community structure in a paddy soil. Sci. Total Environ. 556, 89-97. doi: 10.1016/j.scitotenv.2016.03.010

Toju, H., Tanabe, A. S., Yamamoto, S., and Sato, H. (2012). High-coverage ITS primers for the DNA-based identification of ascomycetes and basidiomycetes in environmental samples. PloS one 7:e40863. doi: 10.1111/1462-2920.13133.x

Tripathi, P., Shah, S., Kashyap, S. D., and Tripathi, A. (2019). Fruit yield and quality characteristics of high density Prunus persica (L.) Batsch plantation intercropped with medicinal and aromatic plants in the Indian Western Himalayas. Agroforest. Syst. 93, 1717-1728. doi: 10.1007/s10457-018-0276-9

Vance, E. D., Brookes, P. C., and Jenkinson, D. S. (1987). An extraction method for measuring soil microbial biomass C. Soil Biol. Biochem. 19, 703-707. doi: 10.1016/0038-0717(87)90052-6

Waldrop, M. P., Holloway, J. M., Smith, D. B., Goldhaber, M. B., Drenovsky, R. E., Scow, K. M., et al. (2017). The interacting roles of climate, soils, and plant production on soil microbial communities at a continental scale. Ecology 98, 1957-1967. doi: 10.1002/ecy.1883

Wan, W., Tan, J., Wang, Y., Qin, Y., He, H., Wu, H., et al. (2020). Responses of the rhizosphere bacterial community in acidic crop soil to $\mathrm{pH}$ : changes in diversity, composition, interaction, and function. Sci. Total Environ. 700:134418. doi: 10.1016/j.scitotenv.2019.134418

Winkelmann, T., Smalla, K., Amelung, W., Baab, G., Grunewaldt-Stocker, G., Kanfra, X., et al. (2019). Apple replant disease: causes and mitigation strategies. Curr. Issues Mol. Biol. 30, 89-106. doi: 10.21775/cimb. 030.089

Yim, B., Nitt, H., Wrede, A., Jacquiod, S., Sørensen, J., Winkelmann, T., et al. (2017). Effects of soil pre-treatment with Basamid\$granules, Brassica juncea, Raphanus sativus and Tagetes patula on bacterial and fungal communities at two replant disease sites. Front. Microbiol. 8:1604.

Yuan, J., Zhang, N., Huang, Q., Raza, W., Li, R., Vivanco, J. M., et al. (2015). Organic acids from root exudates of banana help root colonization of PGPR strain Bacillus amyloliquefaciens NJN-6. Sci. Rep. 5:13438. doi: 10.1038/ srep 13438

Zhalnina, K., Louie, K. B., Hao, Z., Mansoori, N., da Rocha, U. N., Shi, S., et al. (2018). Dynamic root exudate chemistry and microbial substrate preferences drive patterns in rhizosphere microbial community assembly. Nat. Microbiol. 3:470. doi: 10.1038/s41564-018-0129-3

Zhao, J., Zeng, Z., He, X., Chen, H., and Wang, K. (2015). Effects of monoculture and mixed culture of grass and legume forage species on soil microbial community structure under different levels of nitrogen fertilization. Eur. J. Soil Biol. 68, 61-68. doi: 10.1016/j.ejsobi.2015. 03.008

Conflict of Interest: The authors declare that the research was conducted in the absence of any commercial or financial relationships that could be construed as a potential conflict of interest.

Copyright (c) 2021 Zhang, Han, Song, Tian, Song, Hu, Zhang and Yao. This is an open-access article distributed under the terms of the Creative Commons Attribution License (CC BY). The use, distribution or reproduction in other forums is permitted, provided the original author(s) and the copyright owner(s) are credited and that the original publication in this journal is cited, in accordance with accepted academic practice. No use, distribution or reproduction is permitted which does not comply with these terms. 